\title{
17
}

\section{REFIGURING SPACES}

\section{Transformative aspects of migration and tourism}

\section{Stefanie Bürkle}

This visual essay explores the issue of "spatial transformation" through photographs of various places in Berlin (Alexanderplatz, Gendarmenmarkt, Lustgarten, Dong Xuan Center), Korea (Dogil Maeul, Seoul, Songdo), and China (Shenzhen, Window of the World), in which very different cultural ideas of urban space can be found.

In this case, "refiguring spaces" refers to an ongoing transformation of urban space, which is defined by means of the cultural concepts of center and rim, outer and inner spatiality. My photographs often capture spatially marginal situations, which offer a behind-the-scenes peek into these ideas of space. The shift from living urban spaces to empty stages, where the city appears to be nothing more than a backdrop, was not solely caused by the lockdown during the corona outbreak in spring 2020.

The selection of photographs in this essay covers a time frame from 2006 to 2020 and in part originated within the context of the art project "Migrating Spaces and Tourism" (a subproject of the Collaborative Research Center 1265 "Re-Figuration of Spaces"), which explores the overlapping of migration and tourism in physical urban space. I have arranged the single images into a series, a continuous band of images. The absence of captions frees the viewers from a purely content-based classification of the images, transforming them into travelers between the spaces. Isolated motifs reappear in the preceding or following image, thus creating new compositional and content-related connections beyond the images. Objects and perspectives link the pictures and form a new visual texture. Connections and transitions are the focus of the observation. Single images become interrupted, only to be continued when flipping to the next page. Hence, this series of images sheds light on the complex spatial overlapping of tourism and migration and their polycontexturality. 
Art and research project: MIGRATOURISPACE | Space Migration and Tourism Director: Stefanie Bürkle

Assistant director: Janin Walter

Scientific assistance: Ilkin Akpinar, Berit Hummel, Tae Wong Huur, Aaron Lang This visual essay was produced as part of the DFG-financed project "Migrating

Spaces and Tourism." The project is part of the CRC 1265 "Re-Figuration of Spaces" (project number 290045248).

www.migratourispace.de

www.kunst.tu-berlin.de

www.stefanie-buerkle.de

Photography (C) Stefanie Bürkle/VG Bild-Kunst, Bonn 2021 


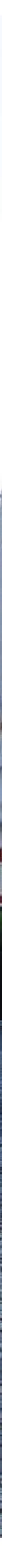




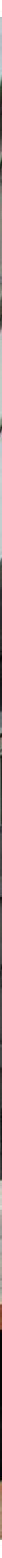




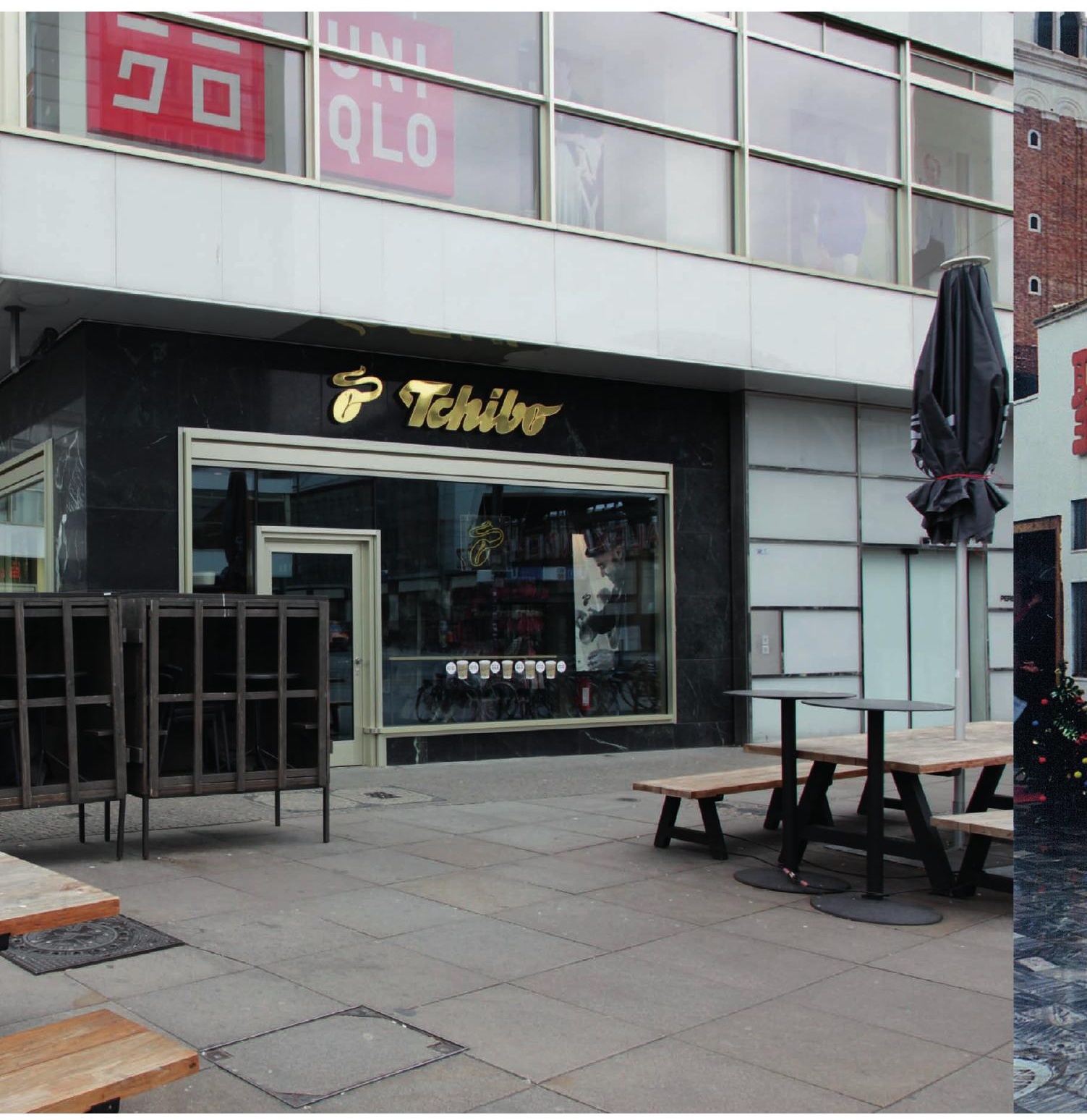




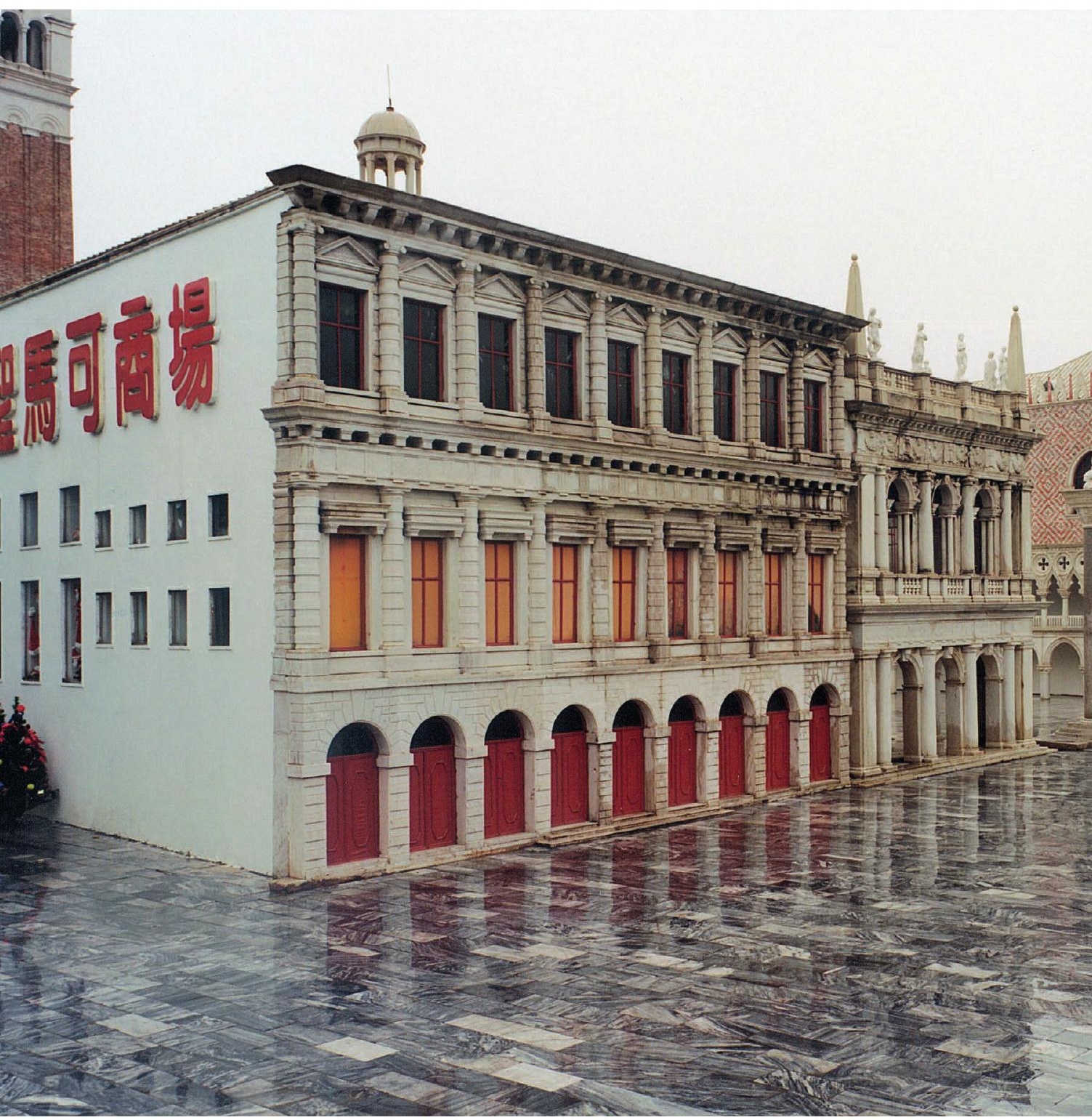




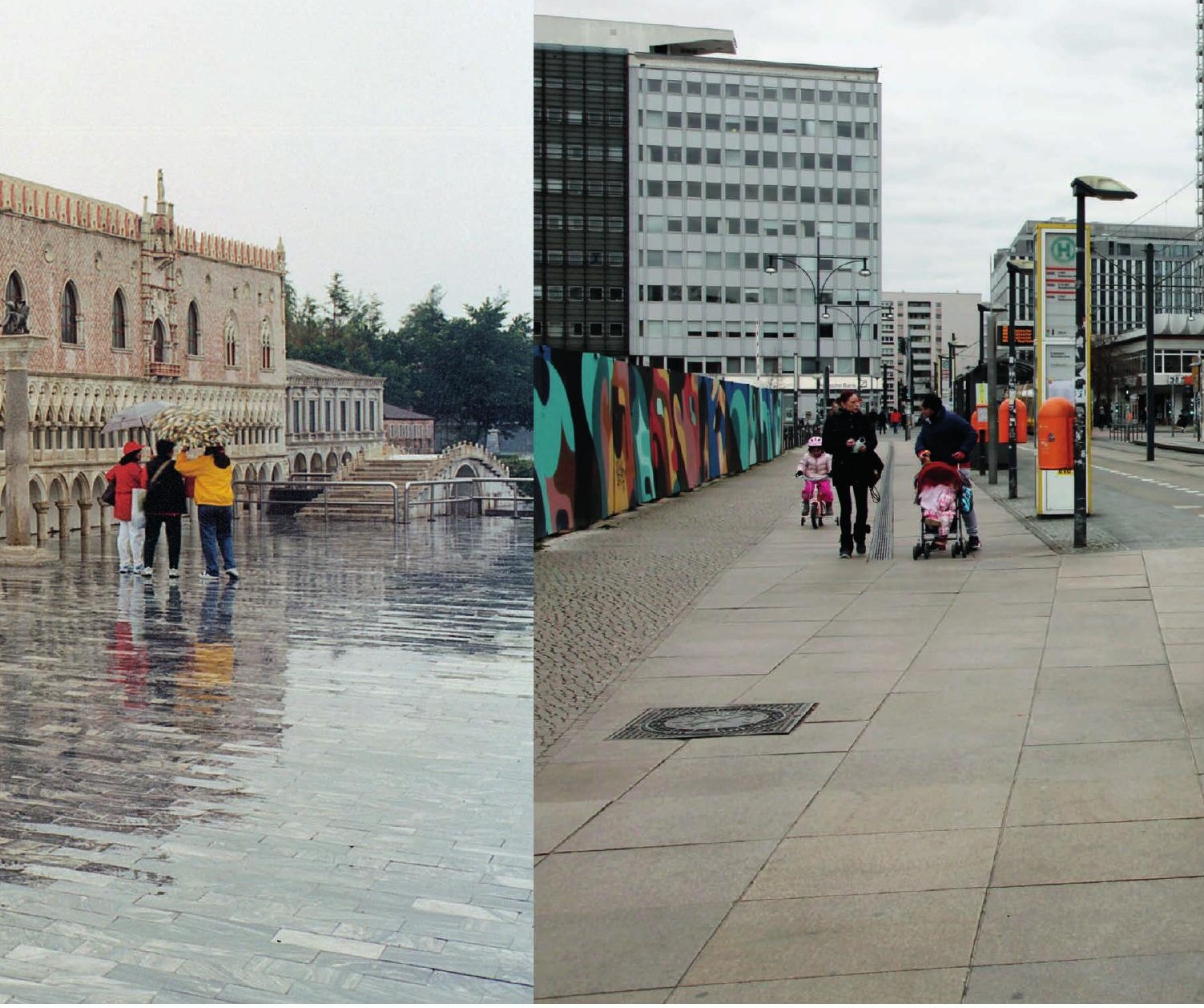




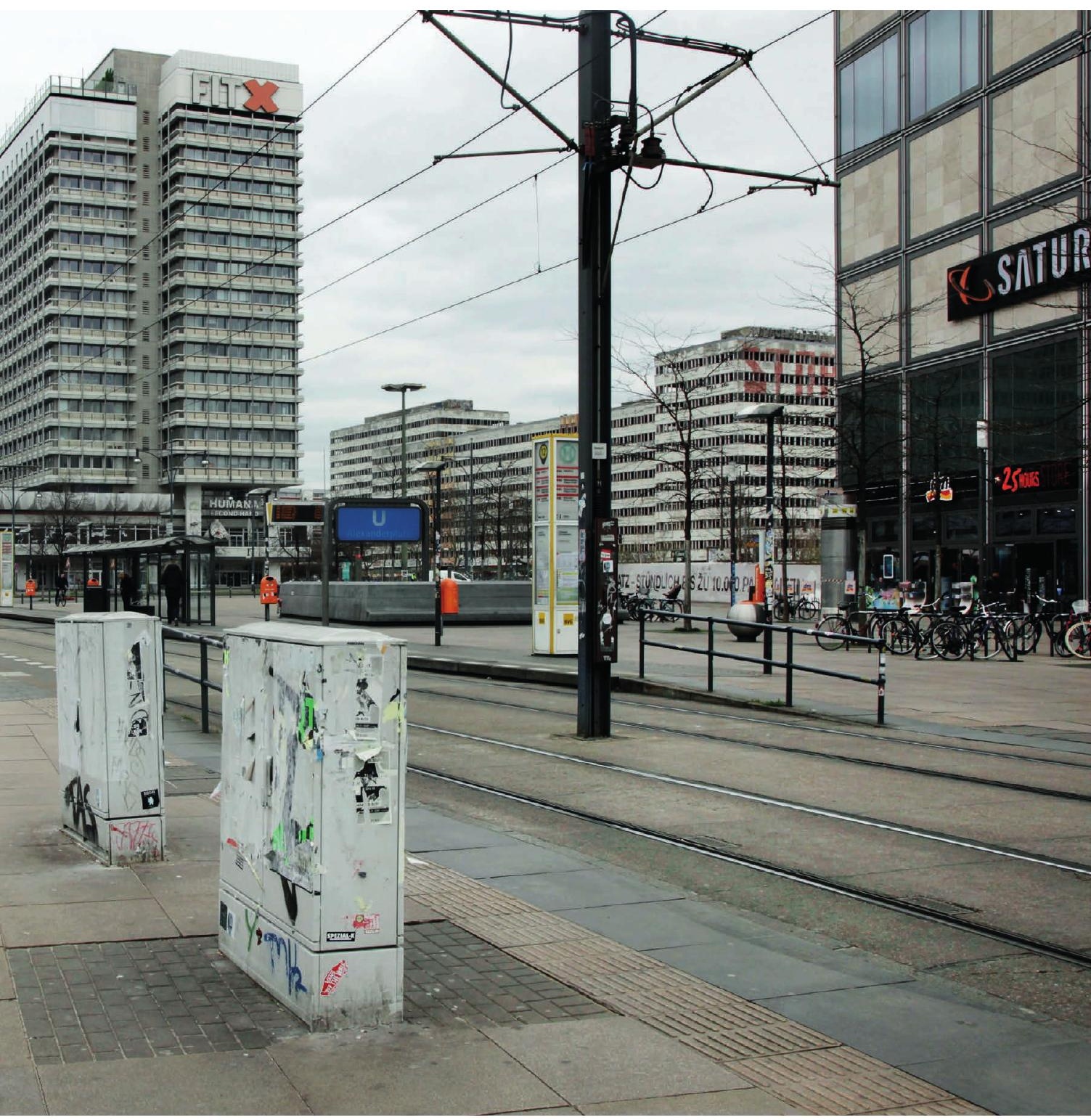




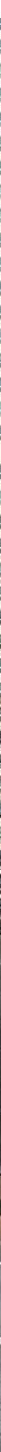




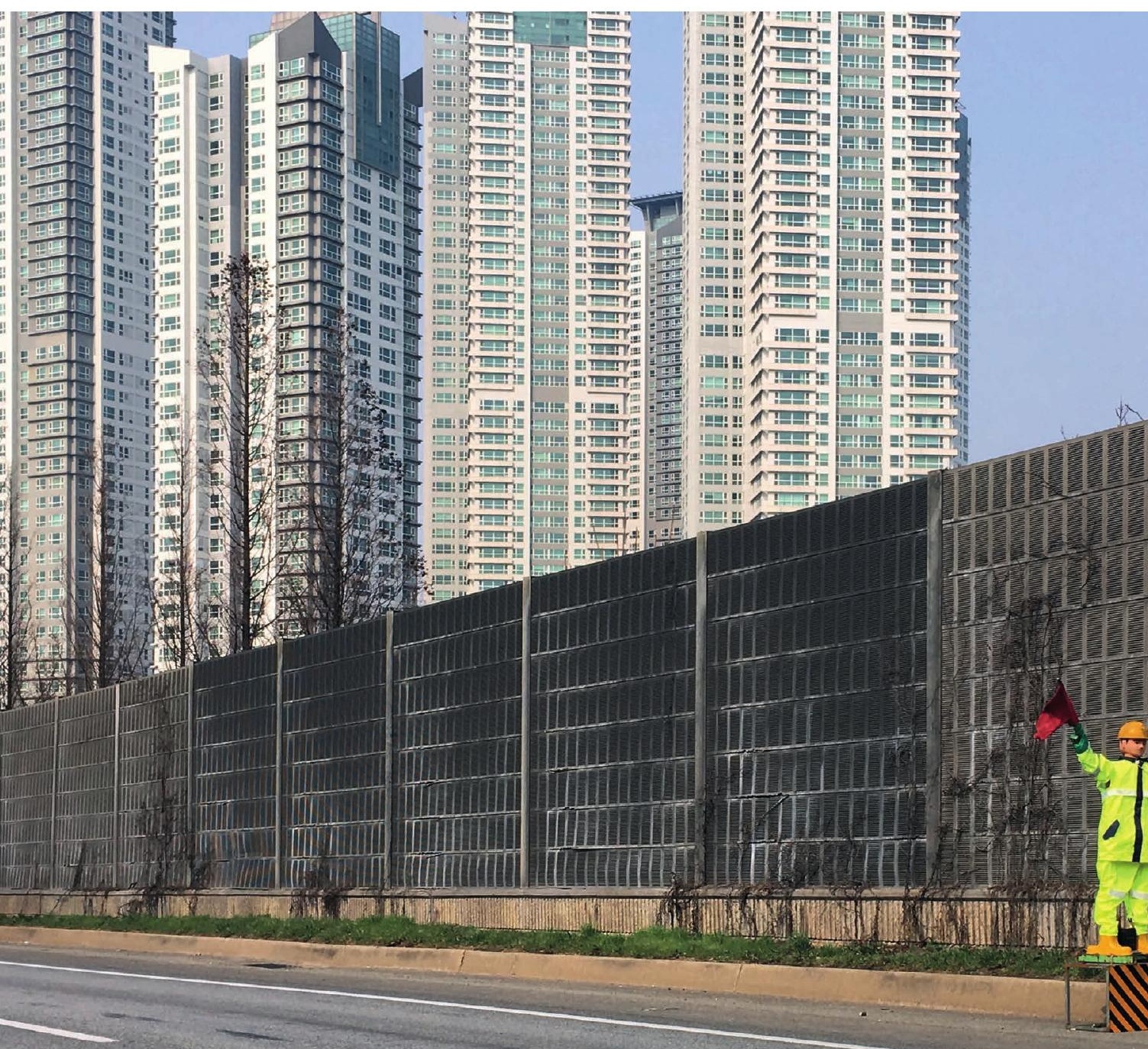



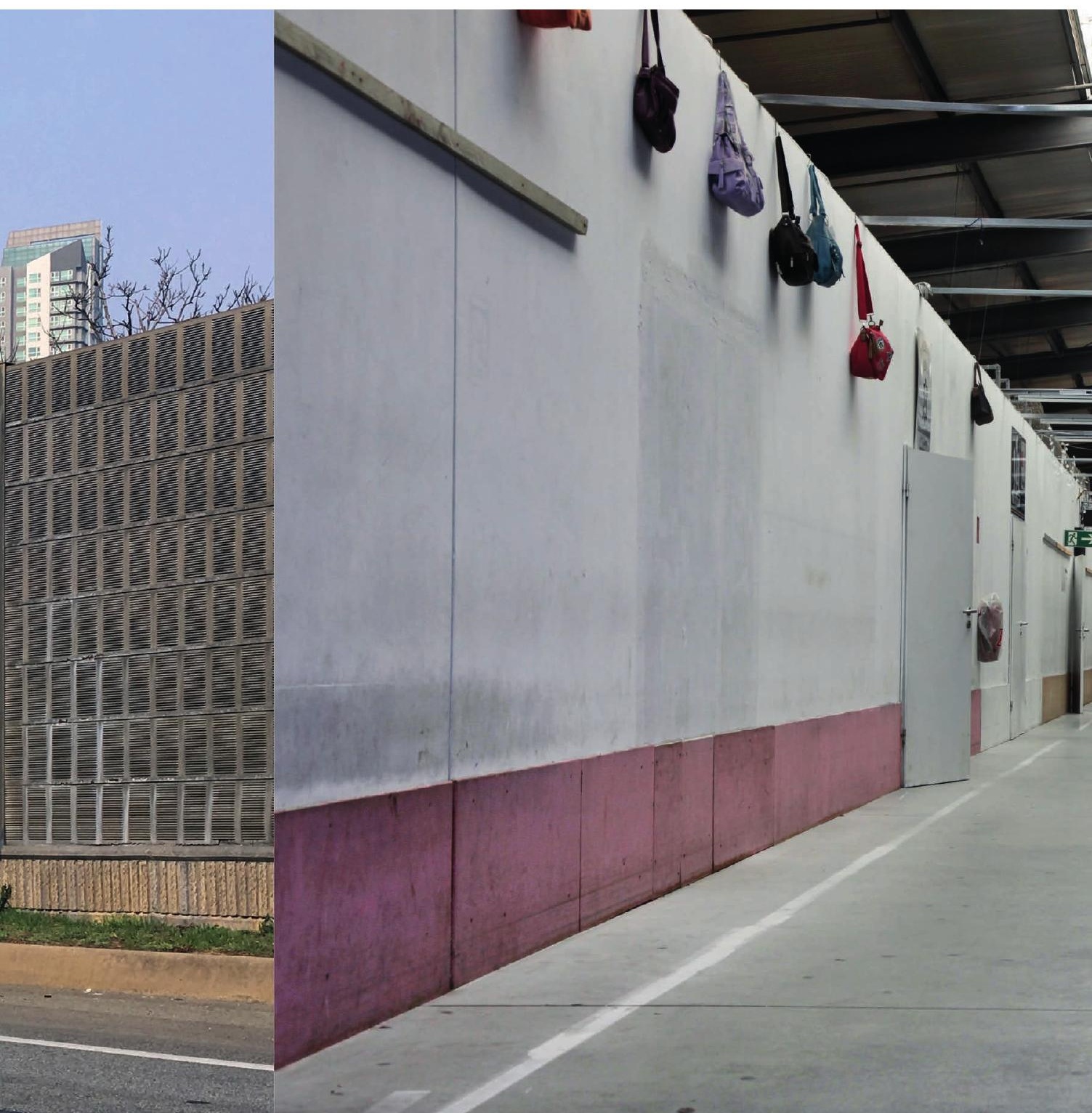


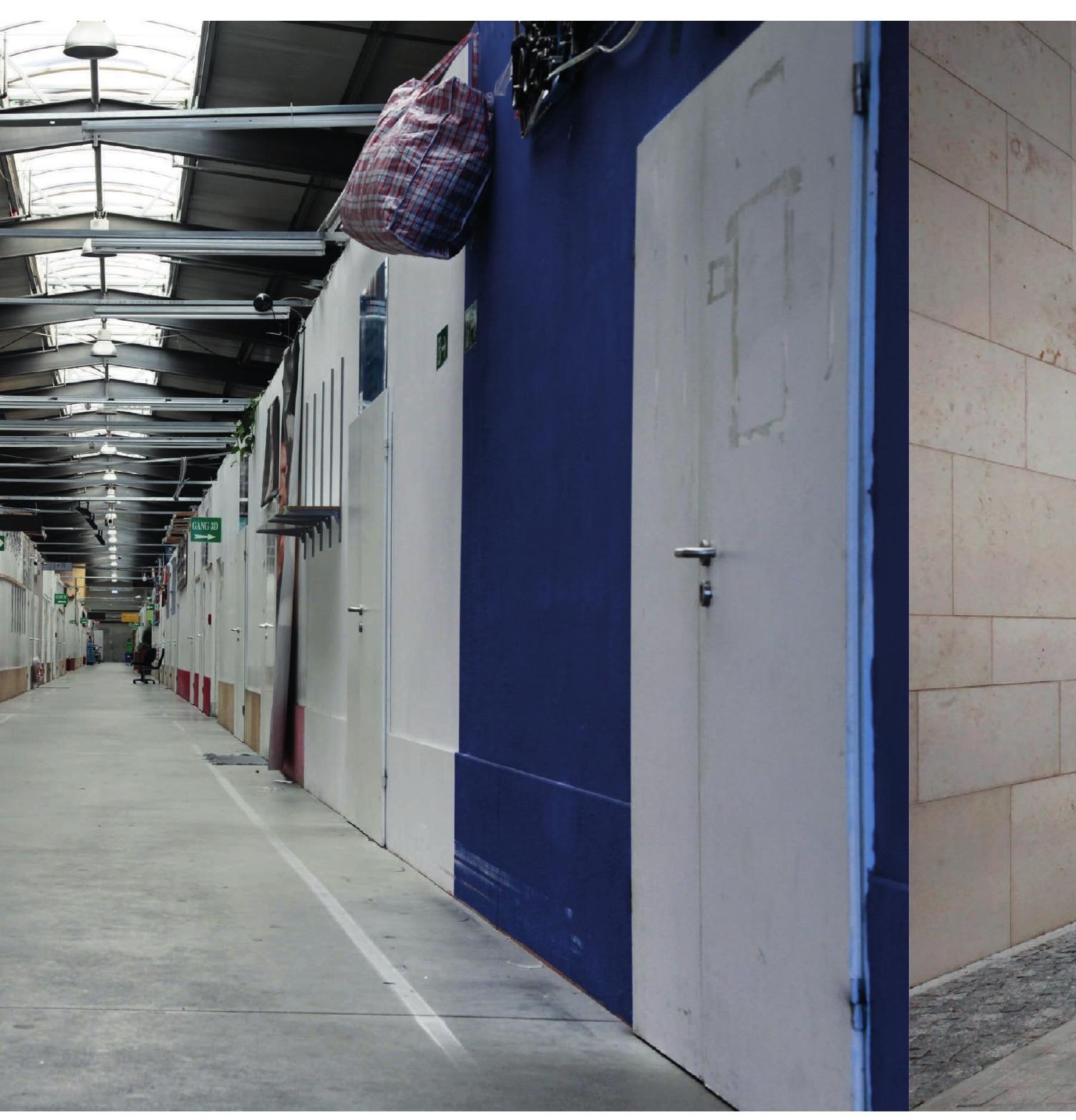




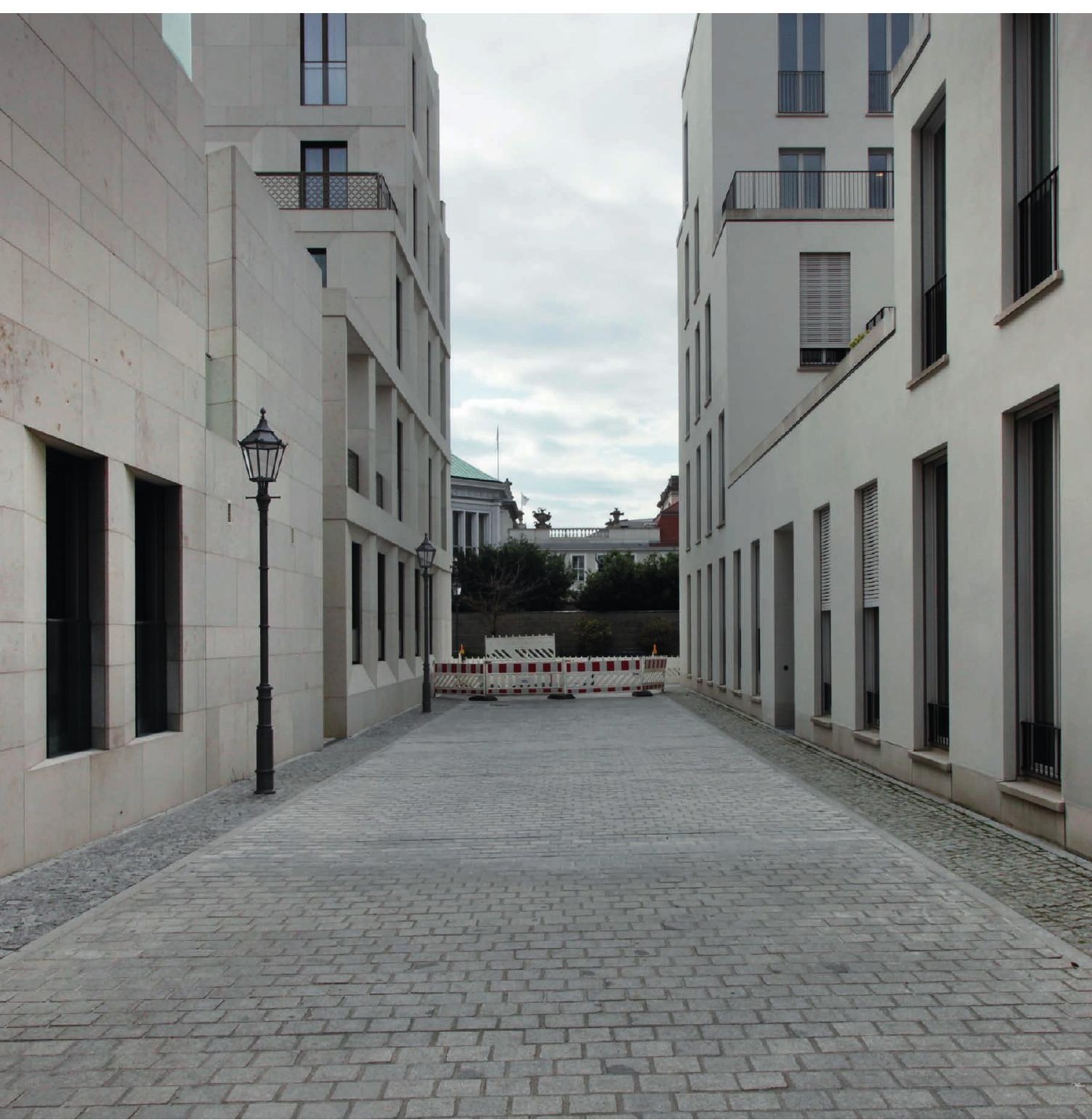




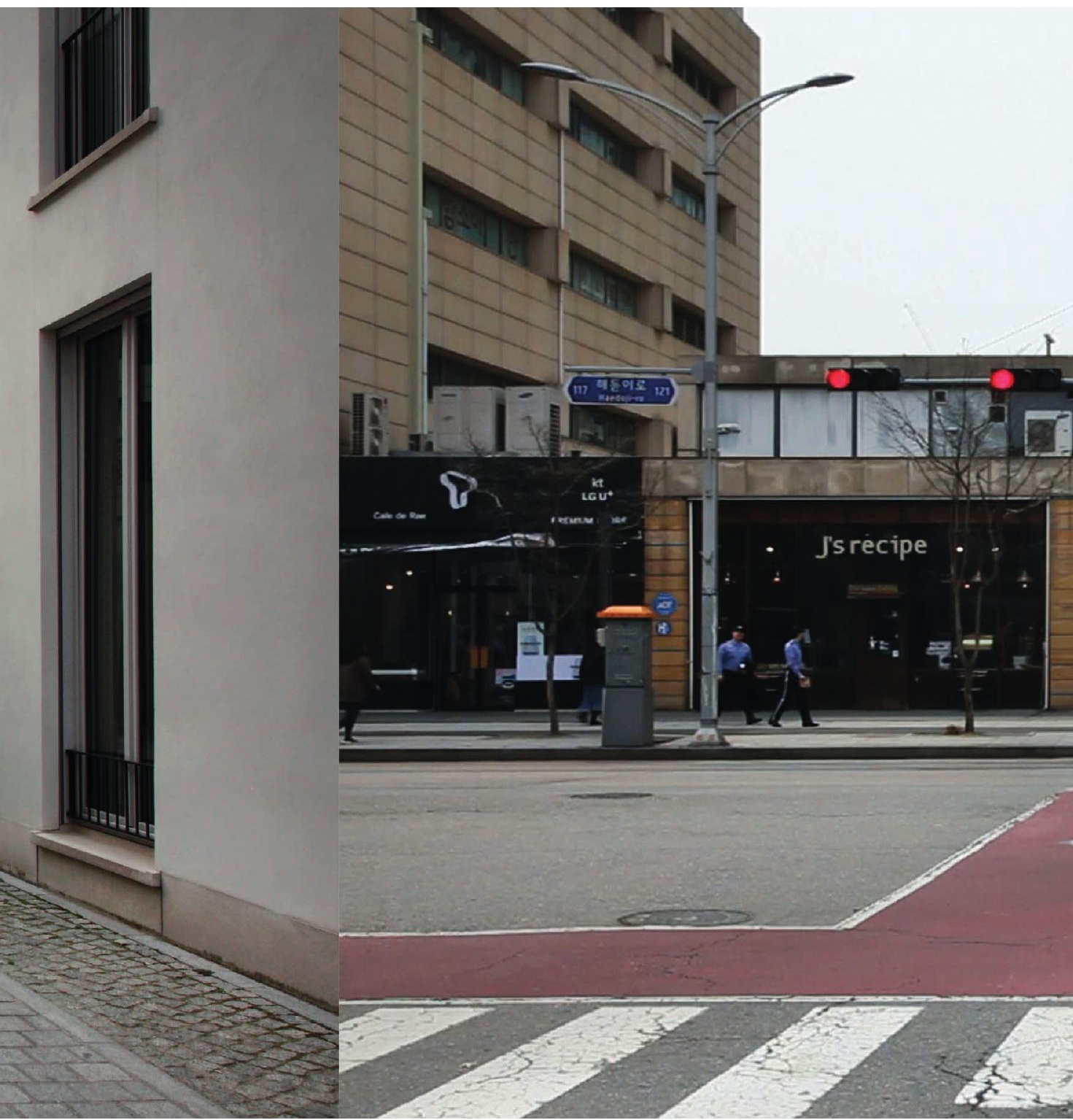



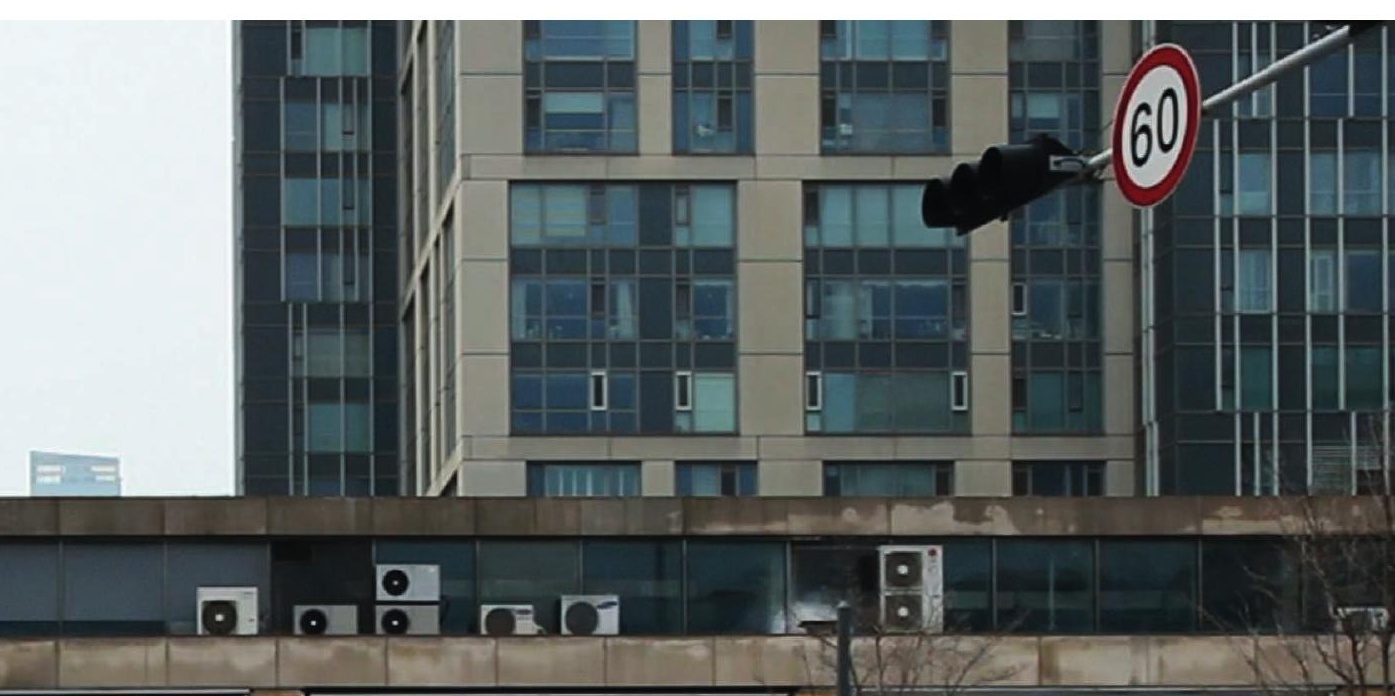

(b) Let: PARIS ABAGUETTE
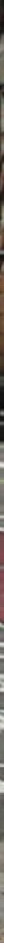


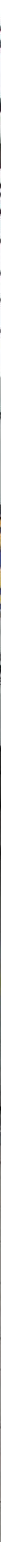




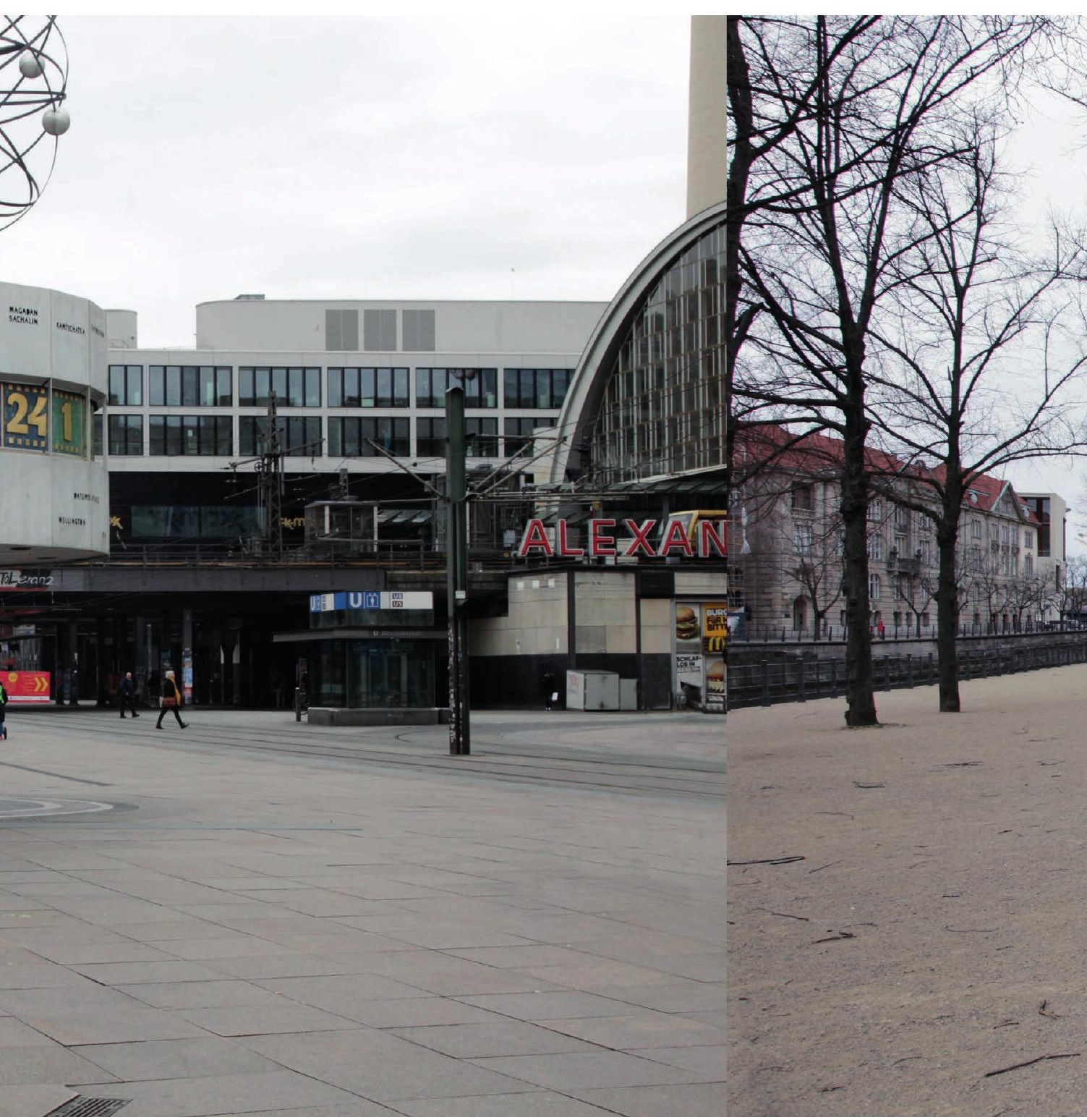




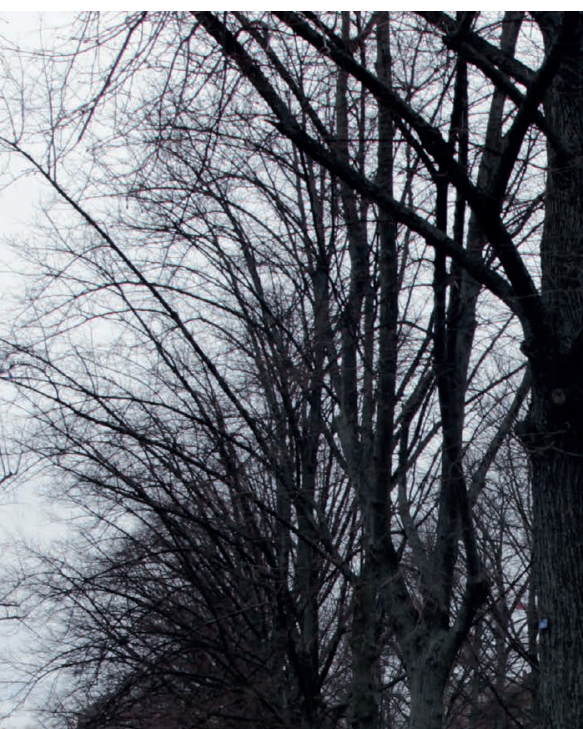

21 - 2 (1)

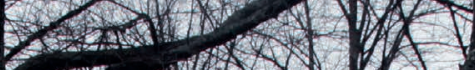

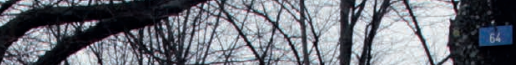

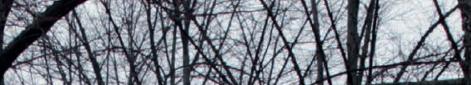
of (Wh Nav 1. (4) 2 - 120

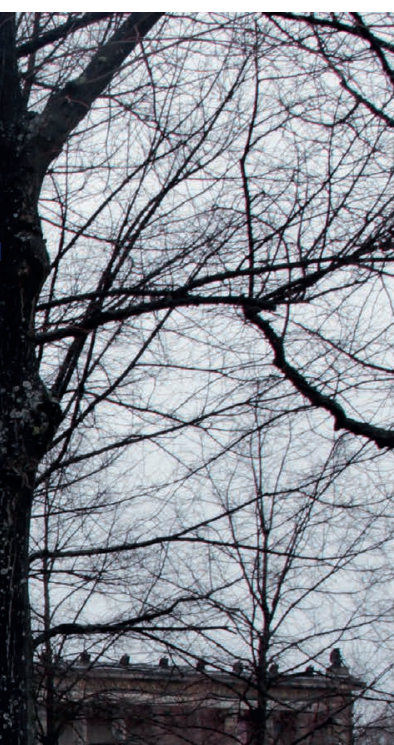

(])

(2)
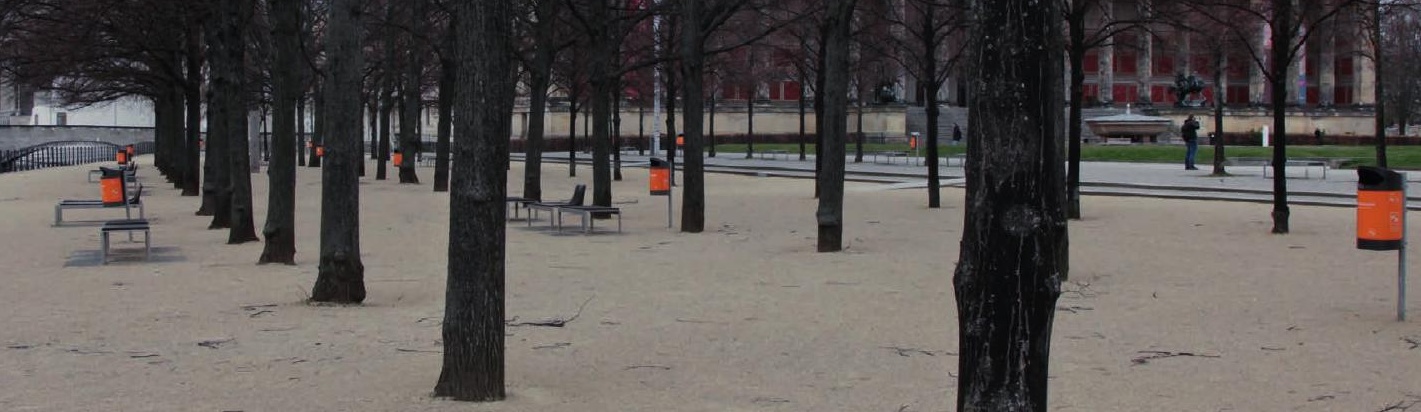


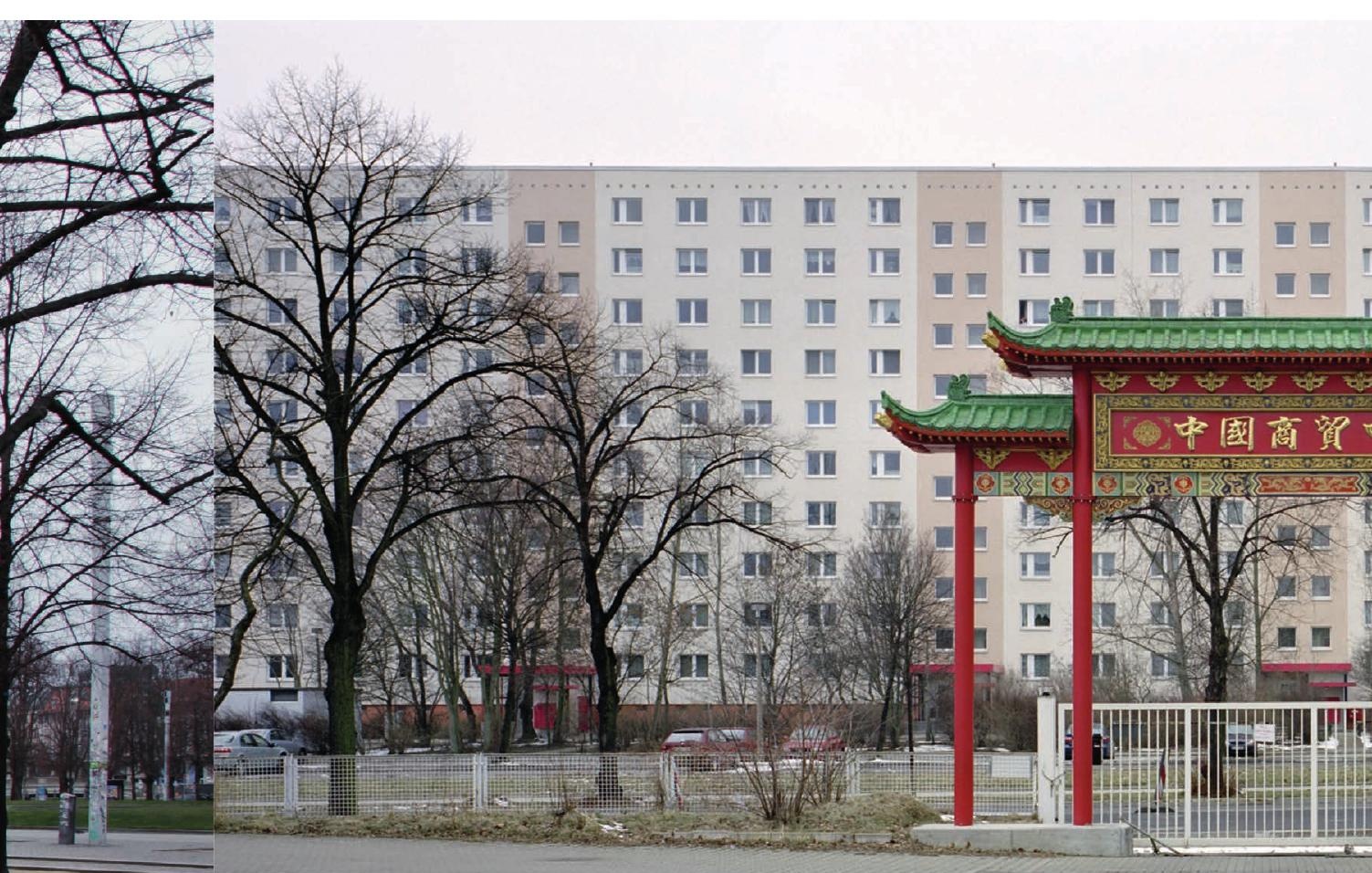




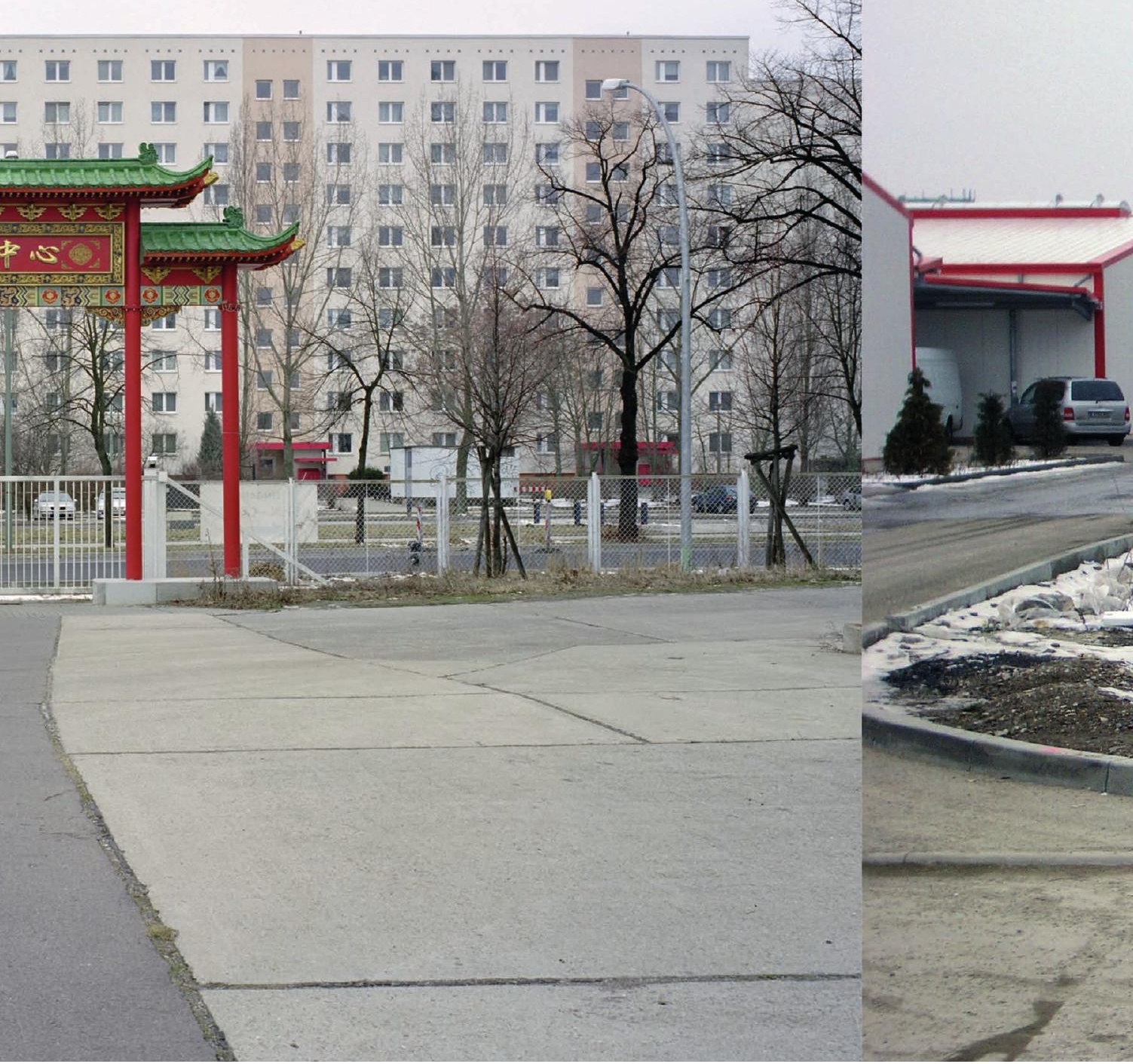




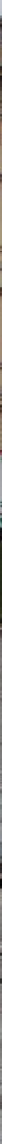


MEII:-

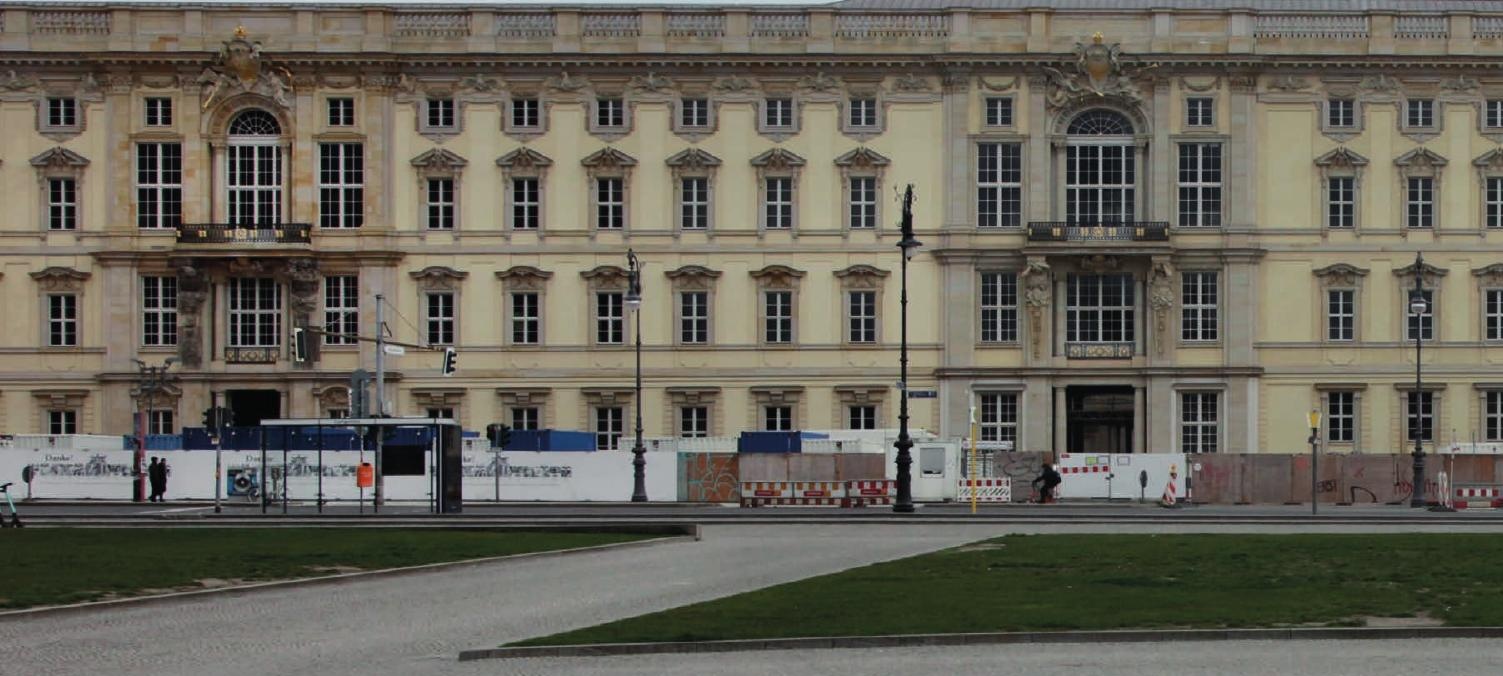

rmans

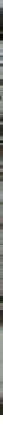




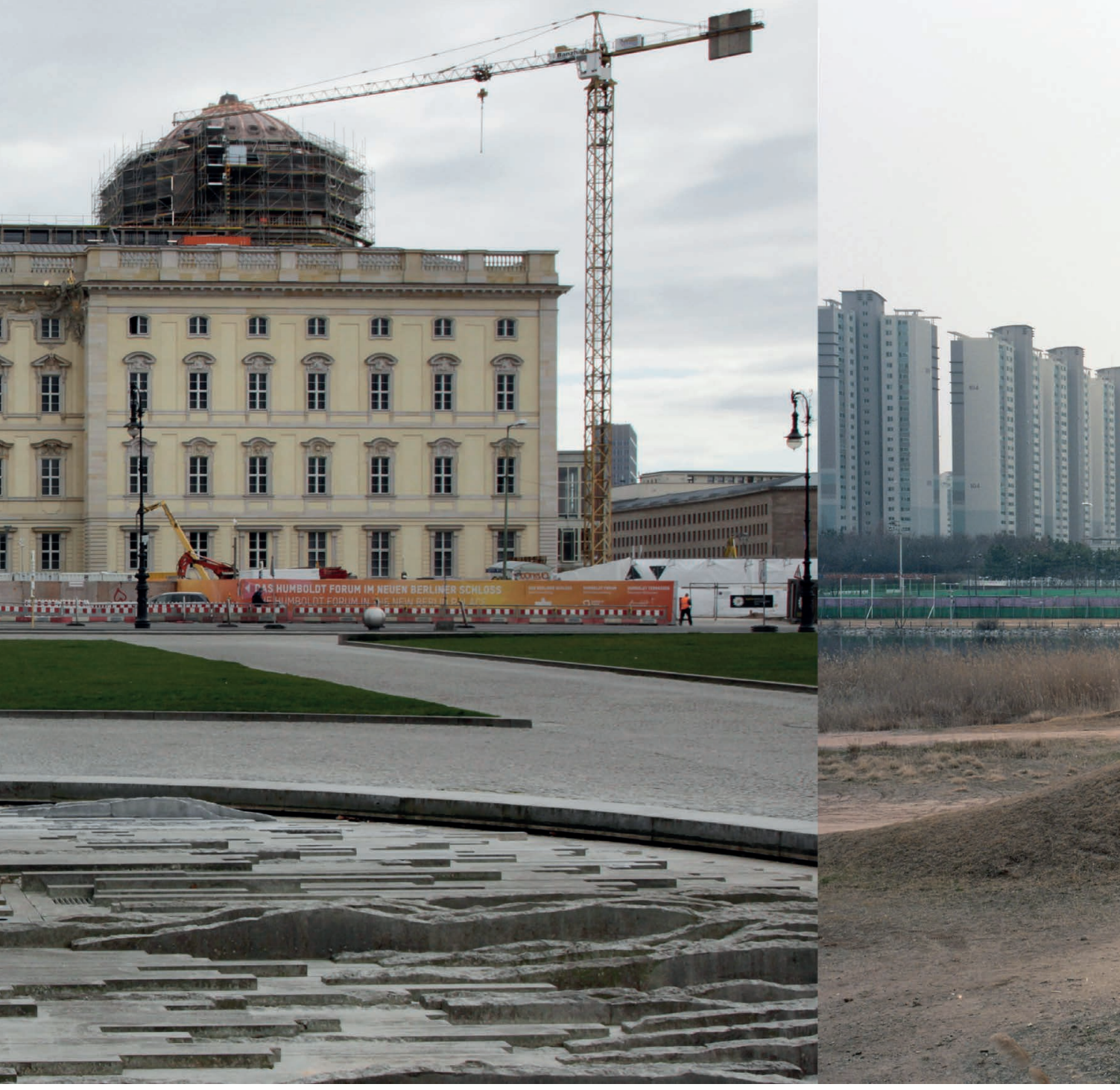




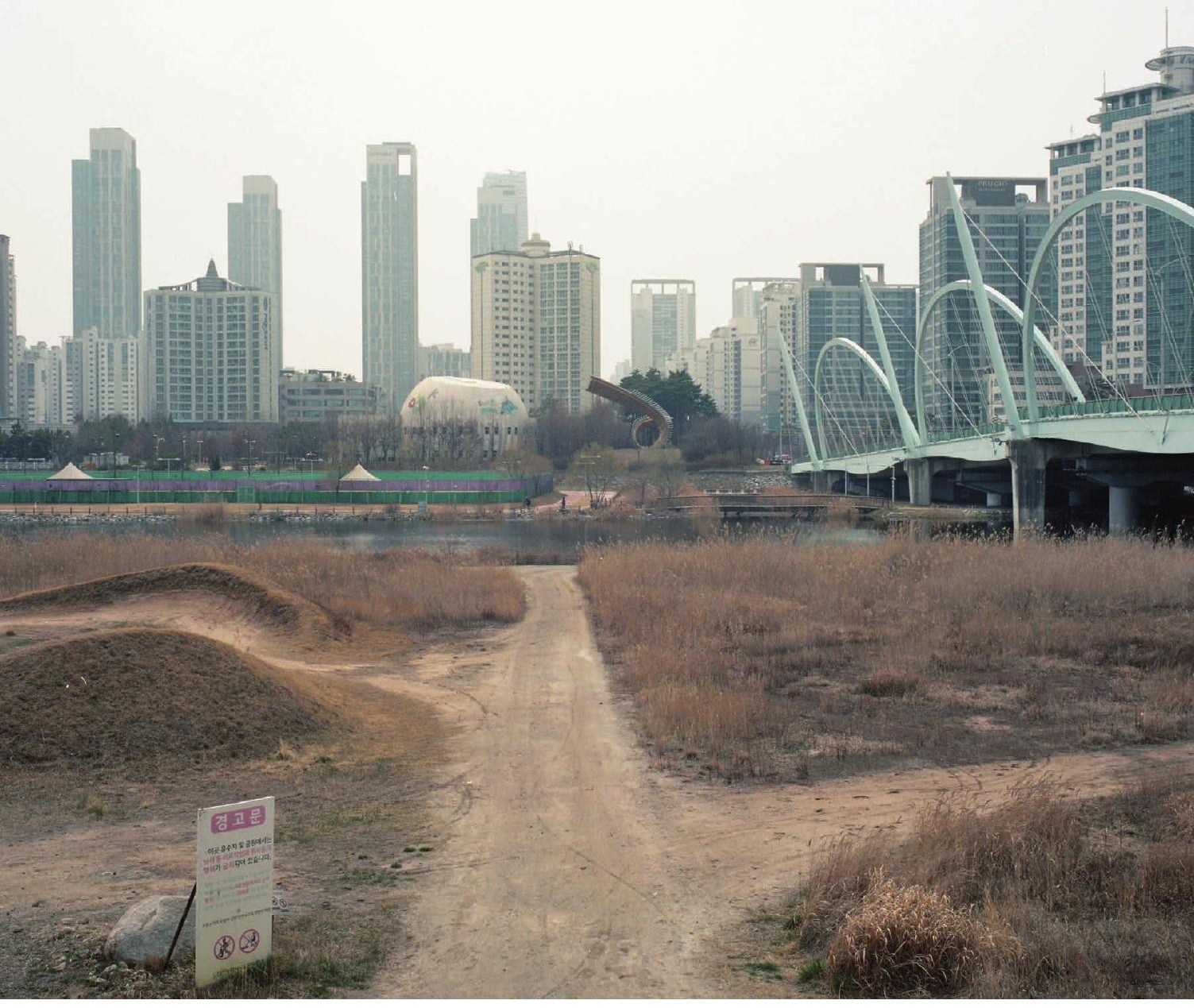

